Entrevista - Diálogos Midiológicos 39

\title{
Le Monde e a cobertura internacional sobre o Brasil: entrevista com Franck Nouchi, médiateur Le Monde
}

Le Monde and the international coverage about Brazil: interview with Franck Nouchi, mediateur Le Monde

Le Monde y la cobertura internacional sobre el Brasil: entrevista con Franck Nouchi, mediateur Le Monde

\section{Franck Nouchi}

(Le Monde. Paris, França)

\section{Entrevista concedida a}

\section{Érika de Moraes ${ }^{1}$}

(Universidade Estadual Paulista Júlio de Mesquita Filho, Faculdade de Arquitetura, Artes e Comunicação, Departamento de Ciências Humanas. Bauru - São Paulo, Brasil)

https://orcid.org/0000-0002-6571-3971

Franck Nouchi é médiateur do jornal Le Monde. Optamos por manter a terminologia original médiateur, pois se trata de uma função diferenciada em relação às

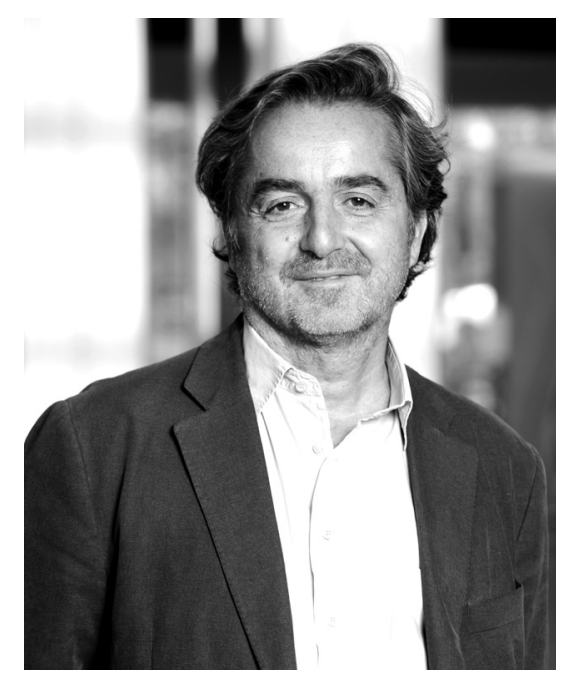
existentes nas redações brasileiras, aproximada à do ombudsman, um responsável pela "mediação" com leitores do jornal e pela (auto)avaliação crítica do veículo. Trata-se de profissional com ampla experiência jornalística, que exerceu por mais de 15 anos a função de redator-chefe, responsável pela coerência editorial do veículo e, na prática, pela conferência de títulos e produção de manchetes de capa (la Une). Um profissional, portanto, de muita credibilidade e com plena autonomia para exercer o seu papel, com independência para, quando considera necessário, publicar colunas analíticas no jornal.

Nouchi é formado em Medicina e iniciou a carreira como jornalista cobrindo as atualidades médicas para Le Monde na década de 1980. Destaca-se em sua carreira o fato de

\footnotetext{
1 A entrevista foi realizada na sede do jornal, no dia 16 de junho de 2017, às 10h da manhã de uma sexta-feira, em francês. Utilizamos um gravador para, posteriormente, transcrevê-la, traduzindo-a para o português. A atividade foi realizada durante estágio de pesquisa pós-doutoral em Paris, realizado na Université Paris-Sorbonne, sob a supervisão do professor Dominique Maingueneau, e com apoio da Fapesp (processo 2016/18915-3). Apesar de termos elaborado previamente um roteiro com perguntas, optamos por deixar a conversa fluir em torno dos temas principais, tendo em vista a prática do “diálogo possível”, conforme propõe Medina (1990). Na edição final do material, reorganizamos a entrevista no formato pergunta-resposta, com objetivo de facilitar a compreensão para o leitor.
} 
ter sido o primeiro a alertar, já em 1983, sobre os riscos de contaminação pelo vírus HIV na transfusão para hemofílicos. Em 1991, fez parte de uma equipe de jornalistas que cobriu um caso de grande impacto sobre sangue contaminado. Foi redator-chefe da Editoria Sociedade e diretor dos Cadernos de Cinema. Em 2003, foi nomeado diretor adjunto da redação de Le Monde. Foi também diretor de Livros e da revista do grupo Le Monde. É ainda autor de "Le cerveau de Voltaire", Editora Flammarion, e de "Sida - Trente Ans de Lutte contre le virus", Edições Le Monde. O jornalista revelou, em entrevista à Whatsupdoc Magazine (2014), que decidiu de vez pelo jornalismo em detrimento da prática da medicina ao se ver diante de um dilema ético-deontológico: respeitar o segredo médico ou revelar informações relevantes.

Refletindo a respeito da cobertura internacional de notícias sobre o Brasil, especialmente em Le Monde, partimos de alguns questionamentos. Por que certos assuntos sobre o Brasil (e não outros) são pautados por um veículo midiático francês? O que faz uma notícia sobre o Brasil ter sentido para um leitor de Le Monde? Ou como se constrói, discursivamente, a relevância para o público? Em primeiro lugar, deve ser considerado que a proposta de Le Monde, segundo confirma seu médiateur, é a de ser um veículo internacional, daí o seu nome "Mundo”. Assim, pautar o Brasil, bem como outros países, é parte da política editorial do veículo.

Le Monde possui uma ampla rede de correspondentes internacionais, com quatro escritórios nos Estados Unidos e outros espalhados em todo o globo. A decisão de ter um correspondente fixo em um país depende da relevância da cobertura e também de condições propícias. Por exemplo, o médiateur nos informa que haveria interesse por parte do jornal em ter escritórios na Argélia e na Venezuela, mas as autoridades desses países dificultam o processo.

Nouchi conta que o jornal recebeu críticas de diversas ordens relacionadas à cobertura da política brasileira na fase do impeachment da Presidente Dilma Rousseff, especialmente de leitores percebidos pelo médiateur como de “extrema esquerda brasileira”. Relata também ter havido, embora em menor quantidade, leitores que se queixaram de uma "cobertura esquerdista”, incluindo leitores brasileiros e franceses. Por essa razão, fez um processo de reflexão sobre essa cobertura, discutido com a correspondente Claire Gatinois, o qual expressou em um artigo publicado na edição impressa do jornal Le Monde na seção "Débats \& Analyses” em 25 de abril de 2016, intitulado: Brésil: " Le Monde » a-t-il été partial? Este artigo foi traduzido na mídia brasileira e, algumas vezes, como é típico do processo de destacamento (MAINGUENEAU, 2010, 2014), teve seus sentidos simplificados.

Na entrevista, o médiateur aborda os desafios do jornalismo na construção da cobertura entendida como informativa, sem deixar de assumir que o veículo hierarquiza informações à sua maneira. E, independentemente de erros e acertos, expressa quantos esforços são mobilizados por aqueles que trabalham com a divulgação de notícias, segundo critérios profissionais. Se, muitas vezes, o jornalismo é criticado por sua cobertura supostamente enviesada, o entrevistado, a seu turno, desabafa: lidar com tantas críticas, às vezes, “é um inferno”! 
Revista Intercom - De maneira geral, quais são os critérios para selecionar as notícias estrangeiras que serão veiculadas pelo aplicativo ${ }^{2}$ Le Monde? De que modo o Brasil faz parte dessa seleção?

Franck Nouchi - Primeiramente, é importante dizer que Le Monde dispõe de uma rede de correspondentes no mundo inteiro. Há países onde há mais correspondentes, sobretudo, o país número 1 são os Estados Unidos, onde há sedes em Washington, Nova York, São Francisco e um grande escritório em Los Angeles que trata da atualidade que se passa durante a noite, a partir de $18 \mathrm{~h}$ no horário da França. Há uma equipe de jornalistas que trabalha durante a noite da França. Se ocorre algo importante enquanto “a França dorme”, esse escritório cobre. Desde muito tempo, Le Monde tem correspondente no Brasil. Consideramos que o Brasil ocupa um espaço preponderante na América do Sul. Há sempre uma relação particular entre a França e o Brasil. Os franceses são muito interessados, por diversas razões, sobre tudo que se passa no Brasil. Há interesse pelos países que são emergentes, o Brasil faz parte do BRICS... faz-se questão de eleger a cobertura do Brasil. Quando é necessária a decisão de fechar um escritório para abrir outro, considera-se que o Brasil é um país importante para ter um correspondente. Há um correspondente na Argentina também. Houve, por um bom tempo, em Santiago, hoje há em Lima, de onde se cobre a parte norte da América do Sul. Gostaríamos muito de ter um correspondente na Venezuela, mas é complicado, há muitos problemas com as autoridades do país. Onde gostaríamos absolutamente de ter uma sede e não temos seria na Argélia. Tivemos um correspondente por longo tempo, mas as autoridades argelinas nos impedem de ter um correspondente permanente. É parecido no Marrocos, lá é complicado. Mas há um correspondente full time na Tunísia, de onde cobre Líbano e Sudão, mas não cobre Argélia e Marrocos. São países complicados, é preciso vir de Paris, ter um visto. Marrocos é um pouco mais simples, mas Argélia é terrivelmente difícil. Então, voilá... depende do país. Há países que nos interessam muito, mas não temos correspondentes, porque não se reúnem as condições de trabalho possíveis.

Revista Intercom - Do ponto de vista do Le Monde, o que faria uma notícia sobre o Brasil ter sentido para um leitor francês? Que tipo de notícia interessa a esse leitor? Quando se pauta uma notícia sobre outro país, a exemplo do Brasil ou Venezuela, em qual público se pensa prioritariamente: no público francês ou nos leitores estrangeiros?

Nouchi - Sem dúvida a resposta é que o Brasil é um país que importa para a nossa cobertura. Um personagem como Lula é muito popular aqui na França, o seguimos muito. Sua responsabilidade política é reclamada, solicitada. Então, para nós é importante cobrir Lula, contar o que ele diz. Em todo caso, isso interessa ao público que lê Le Monde. Não

2 Trata-se da versão em aplicativo (para tablets e smartphones) do jornal Le Monde, cujas notícias podem ser as mesmas da edição impressa, com a possibilidade de atualização. O jornal se reserva o direito de publicar parte do conteúdo somente na versão impressa ou para assinantes da versão digital. 
é todo mundo que lê Le Monde, mas, na versão em papel, são 1,5 a 2 milhões de pessoas. E na Internet perto de 10 milhões de pessoas. Há franceses e estrangeiros, bem-entendido. Podemos falar de política, mas também de cultura, de esportes... Evidentemente, falar da economia, que interessa a certo público. E eu me dou conta, pois sou médiateur, que, às vezes, nossa cobertura das atualidades no Brasil provoca reações muito fortes nos leitores. Quando a antiga presidente Madame Rousseff foi destituída, recebemos muita correspondência de leitores que não estavam de acordo com a cobertura de Le Monde sobre o Brasil. Havia três grupos de leitores que me escreveram: pessoas da França, do Brasil e franceses que vivem no Brasil. Escrevi uma crônica ${ }^{3}$ sobre a cobertura do Brasil por Le Monde, de tanto que houve reações (NOUCHI, 2016). Nas correspondências, havia um pouco de tudo. Em geral, como sou médiateur, não fiquei contente, pois as pessoas não estavam contentes. Em geral, diziam que não defendíamos Dilma Rousseff, muitos, muitos leitores. De minha parte, fiz um grande trabalho com a correspondente do Brasil e com o editor internacional, conversei com brasileiros que eu conhecia, para tentar compreender se cometemos erros, para tentar compreender títulos, editoriais, tentamos descobrir se havíamos cometido erros. Tentamos de todo modo respeitar as regras de títulos informativos. Eventualmente, talvez se aventurando um pouco em alguma formulação mal colocada. Então, fiz uma crônica sobre o tema. Houve também leitores que disseram que não fomos críticos. Que defendemos Lula. Houve um pouco de tudo. Tentamos compreender. Então, trabalhei muito com a correspondente para compreender o porquê dessa reação, especialmente da parte de brasileiros. Isso nos indicou que há muitos brasileiros que leem Le Monde. Fiquei surpreso que minha crônica tenha sido traduzida por muitos veículos brasileiros. Tive a confirmação de que nossa maneira de cobrir o Brasil tem importância para certas pessoas - não digo para todo mundo, mas para certas pessoas. Há interesse pelo que Le Monde pensa sobre o Brasil. Sei disso porque recebi dezenas de cartas e e-mails de pessoas reagindo ao tema. E tudo isso mostra que é muito difícil a cobertura do Brasil. É preciso ser muito prudente e, ao mesmo tempo, muito presente. O desafio que temos - e vamos continuar, evidentemente - é assegurar a cobertura. Não é a cobertura dos Estados Unidos, é certo, mas é uma cobertura importante.

Revista Intercom - Há assuntos sobre o Brasil que interessam mais à cobertura de Le Monde? Há esforços para um jornalismo informativo, mas também se busca a interpretação? Os títulos das matérias buscam priorizar o informativo?

Nouchi - Deixe-me detalhar algumas coisas. A jornalista correspondente no Brasil é especialista em economia. Demandamos que preste atenção na economia do país, nas empresas, na espécie de emergência internacional de um grande país na cena internacional. Em todo caso, política e economia se misturam muito. Buscamos uma cobertura informativa, mas nos reservamos o direito de fazer análises sobre o Brasil, de comentar o que se passa,

3 NOUCHI, F. Brésil: « Le Monde » a-t-il été partial? Le Monde, “Débats \& Analyses”, édition de 25.04.2016. 
pelo intermédio do editorial. O jornal se engaja, exprime uma posição que é a posição de Le Monde. A correspondente pode fazer artigos mais analíticos. Então, pode haver títulos que são menos informativos e mais analíticos. São três tipos de artigos. Na página de debates de Le Monde, há artigos escritos por pessoas exteriores ao jornal, mas que são especialistas sobre o Brasil. Sejam brasileiros ou não, podem publicar artigos sobre um tema que conheçam bem sobre o Brasil, com um ponto de vista pessoal, que publicamos na seção “Débats \& Analyses” e no website. O papel da página de debates é dar voz a pontos de vista que são, às vezes, contraditórios. Às vezes, publicamos artigos que trazem o ponto de vista do poder brasileiro e, outras vezes, de articulistas que são muito críticos ao Brasil. Sempre recebemos críticas. Se escrevemos artigos contra Temer, há quem vá escrever: vocês são esquerdistas, a favor de Lula, de PT... é muito complicado! São feitas reportagens, enquetes, entrevistas, análises, editorial... esforços para cobrir um grande país.

Revista Intercom - Observamos que houve contextualização em uma matéria sobre Eduardo Cunha, antes mesmo do impeachment da Presidente Dilma, que o mostrava como responsável pelo pedido de destituição da presidente e, ao mesmo tempo, envolvido com outras suspeitas.

Nouchi - Então, espera... Isso é o que você diz. Você é jornalista, você é professora de jornalismo, você o sabe e eu lhe agradeço muito por dizê-lo, mas saiba que muitos brasileiros não pensam assim. Quer dizer que eles nos culparam de ter retomado. Enfim, de ter mesmo retomado a informação de acordo com a qual Cunha tentava levar até o fim um procedimento de impeachment, enquanto na época ele não era limpo. Na época, não se sabia exatamente o que ele tinha feito. E então nos acusaram de retransmitir a ação de Cunha e de ser, de alguma forma, aliados aos objetivos dele. Você não pode imaginar a quantidade de leitores brasileiros muito ideólogos e muito marcados à esquerda que culparam os artigos, que eu acho equilibrados, os quais você citou. É complicado para a cobertura da correspondente que está em São Paulo. Ela me disse: é incrível o número de correspondência que recebo! Li essa correspondência, estou certo que não havia problema e, ao mesmo tempo, havia uma avalanche de críticas, de que fazíamos o jogo de Temer ou de Cunha. Sabemos que nossa correspondente trabalha bem, mas trabalha sobre a vigilância de um grande número de leitores brasileiros (ou mesmo franceses que vivem no Brasil) que são muito engajados politicamente e que têm a ideia de que Le Monde pouco informava. Em outra etapa, nós fazemos comentários. É por isso que enfatizamos bastante a diferença entre informação, comentário e página de debate. O que você diz não é sempre compreendido pelo leitor. E em particular por certos leitores brasileiros que têm uma tendência a reagir muito rapidamente e, às vezes, violentamente. Há muitos problemas que fazem reagir leitores sobre a cobertura internacional. Um que é terrível para nós é a cobertura sobre Israel e Palestina. Israel e Palestina são países cuja cobertura é muito 
difícil, sempre provoca muitas reações. Recebemos uma avalanche de cartas. Em relação a qualquer coisa que escrevemos, recebemos reações de todos os sentidos: você é pró-Israel, você é pró-Palestina, você é pró-Arábia Saudita, Catar... É um inferno. E é necessário tentar informar calmamente, dizer o que se passa. Cobrir a Rússia é complicado também. Às vezes, há pessoas que me escrevem e tenho a impressão que são pessoas ligadas a Putin. Mas o Brasil é um caso muito particular. Sei que são brasileiros que nos escrevem, não são franceses disfarçados. São pessoas ligadas ao Le Monde, que concordam com a importância do que escreve Le Monde. Mas o que lhes importa é o engajamento político. Ou pode ser o cegamento político, não sei..., mas há outro lado também. Pessoas de direita no Brasil, muito instruídas, que não suportam o que escrevemos, interpretam o que escrevemos da seguinte maneira: “vocês são irremediavelmente um jornal esquerdista”. Isso acontece também, de forma menos numerosa, mas existe.

Revista Intercom - Observamos que a palavra "Brasil” está quase sempre presente em títulos de notícia sobre o país, mas há exceções. Há uma regra sobre isso? Lula, por exemplo, parece dispensar o uso da palavra Brasil. Ele é mais conhecido que outras personalidades brasileiras, certo? Muito mais conhecido do que Temer?

Nouchi - Sim, muito mais conhecido! Nem se compara. Lula é como Obama! Diz-se Lula e todo mundo sabe quem é. Pelé era parecido, na época. Se você diz Pelé, não há necessidade de dizer Brasil. O rei Pelé é rei aqui também. É parecido. Não há necessidade de dizer Brasil. Há pessoas como essas que são autoridades mundiais. Por uma série de razões, assim é Lula. Se dizemos Dilma, devemos dizer Brasil. Se dizemos Temer, devemos dizer Brasil. Há vários leitores que conhecem, sabem que se trata do Presidente do Brasil, mas outros não, sobretudo na Internet. Então, é necessário pensar a questão do título, que às vezes é complicada, isso me preocupa. Os títulos não são os mesmos na versão em papel ou na Internet. Na Internet, se dirigem a milhões e milhões de pessoas. E, se é feita uma sondagem entre essas pessoas (claro, não entre os brasileiros, mas entre leitores da América Latina, por exemplo), nos damos conta que o nome Temer é absolutamente desconhecido. Lula é um caso particular. Há poucos líderes políticos como ele, sobre os quais não há necessidade de dizer muito. Merkel, aqui na França, é assim, não é preciso dizer Alemanha. O nome do primeiro ministro da Itália atualmente, em nível mundial, não se sabe qual é. Não se conhece o seu nome. É necessário dizer o seu nome, Presidente do Conselho italiano. Com Berlusconi não havia necessidade de dizer o nome. É a regra do jornalismo.

Revista Intercom - As agências de notícias são bastante utilizadas, mesmo com a presença de correspondentes em diversos países? A utilização de agências de notícias pode fazer com que os títulos sejam mais "globalizados” ou sempre há uma adaptação para o perfil de Le Monde? 
Nouchi - Le Monde assina todas as grandes agências de notícias. É muito importante ter essas assinaturas. Geralmente são notícias que daremos de maneira curta, quando nos servimos das agências de notícias (France Presse, Reuters). Se há uma reportagem sobre a Amazônia etc., vamos trabalhar com a correspondente, se há pessoas aqui em Paris que se ocupam da América Latina, podemos utilizá-las. Há jornalistas aqui que conhecem muito bem o Brasil, a América Latina. Por exemplo, temos jornalistas que já foram correspondentes no Brasil e retornaram para cá. Então, podem trabalhar um pouco sobre o Brasil. Então, nos servimos também desses trabalhos, bem como das agências, porque temos confiança nelas. Mas tentamos o máximo possível [ter uma cobertura personalizada]. Depende um pouco se falamos do site ou do jornal de papel. O jornal de papel tem mais valor jornalístico. Nós consideramos que a cobertura especial é para o jornal impresso, onde propomos um trabalho mais longo, para o jornal ou para a revista. Em termos de pesquisa, de fotos... Há também a revista: para a revista, podemos propor um tratamento aprofundado sobre o Brasil. Frequentemente, a correspondente escreve para a revista, para contar sobre assuntos a respeito da sociedade brasileira, a cultura, a moda, o esporte no Brasil etc. Mas as agências de imprensa são importantes. No Brasil, por exemplo, há uma forte presença da Agência France Press, então vamos nos servir disso.

Revista Intercom - Poderia falar um pouco sobre o processo de edição de títulos e de escolha para o jornal e o aplicativo Le Monde? Há um editor responsável ou vários jornalistas participam desse processo?

Nouchi - O jornalista que escreve o artigo, em geral, propõe o título, o subtítulo ou linha fina (titre, sur-titre, chapeau). Mas, depois, o artigo será lido por um editor, que pode mudar o título e a linha fina. Depois, é relido por um editor-chefe (chef en service), depois pelo redatorchefe (redacteur en chef). Todos têm o direito de mudar o título e a linha fina. Isso se passa no interior do jornal. Quanto à capa do jornal (la Une), é o redator-chefe que faz o título. Fiz isso por 15 a 20 anos, como era redator-chefe e diretor da redação, era eu que fazia os títulos que apareciam na capa do jornal. A gente pode se equivocar. Não vamos fazer o título da mesma maneira para a notícia no interior e um título de capa. Uma chamada de capa é uma espécie de vitrine de jornal. Então, você sabe, não é da mesma maneira um título no interior e na capa. Os correspondentes, às vezes, não ficam contentes quando refazemos o título. Às vezes, consideram o novo título malfeito, isso acontece. E há um problema muito tolo que é o problema de fuso horário, que afeta a comunicação com o jornalista correspondente. Quando vemos esses artigos, o correspondente pode já ter ido dormir. Às vezes, é possível falar com ele, às vezes não. Às vezes, por não conseguirmos fazer uma questão ao correspondente, decidimos rearranjar. E, às vezes, a gente se equivoca. Isso acontece em todo jornal do mundo. O problema de fuso horário é complicado para o jornalista que está muito longe e não pode ter o olhar fixo sobre o artigo, não pode "seguir” o artigo. 
Revista Intercom - No aplicativo, pode haver uma mudança de título ou eventuais correções e atualizações?

Nouchi - Sim, isso acontece, enquanto no papel não se pode fazer isso: no jornal impresso, é algo definitivo. Na Internet, isso acontece, podemos mudar se a correspondente telefona e argumenta que o título da Internet não está bom, podemos atualizar um pouco. Na Internet, tudo pode mudar, a qualquer tempo, enquanto no papel não se pode mudar. E é algo complicado, devido ao valor do que está impresso em papel. Para muitos leitores, é isso que conta. E isso se passa frequentemente com leitores franceses, porque Le Monde em papel é lido hoje praticamente apenas na França. Salvo que é possível ler em formato PDF pelo mundo inteiro. Pelo mundo inteiro, pessoas como você podem ter acesso à versão em papel em um PDF por meio da Internet. Eu mesmo, outro dia, fiz uma crônica e o título não é o mesmo no papel e na Internet. O bom título é o da versão online e não no papel. Por uma razão idiota, houve uma mudança no título da minha crônica. E leitores do mundo inteiro viram isso e me escreveram perguntando sobre o porquê dessa diferença. Precisei explicar etc. A gente descobre isso... A rapidez da Internet, a força da Internet... O fato de que há muita gente que lê Le Monde na Internet e no papel, isso traz consequências. Na Internet, não há todo o conteúdo. Há muitos artigos, mas não tudo. Isso é frequentemente motivo de mal-entendido: pensar que a cobertura do Monde é a cobertura gratuita de Internet. Por exemplo, sobre o Brasil, pela Internet, haverá muitos artigos de agência, de síntese de informação. E poucos artigos de aprofundamento. Para ler os artigos de Claire Gatinois [a correspondente], é preciso assinar. Temos necessidade de assinantes. The New York Times utiliza o sistema de Paywall, você tem cinco artigos gratuitos e é preciso pagar para ter os demais. Nós temos nosso sistema, para ler todos os artigos, é preciso assinar. Às vezes, isso é um mal-entendido: pensar que nossa cobertura sobre o Brasil é apenas aquela. Então, é preciso dizer que a verdadeira cobertura, em termos de mais valor, é a cobertura paga.

Revista Intercom - O senhor mencionou três tipos de leitores sobre o Brasil...

Nouchi - Franceses; brasileiros; e residentes em um ou outro país: franceses que vivem no Brasil e brasileiros que vivem na França.

Revista Intercom - Quando se trata de notícias sobre outro país (como o Brasil, para abordarmos nosso exemplo), tem-se em vista um público específico ou o leitor internacional, de uma maneira geral?

Nouchi - Não há um público específico. Cobrimos o Brasil como cobrimos outro país. Por exemplo, no caso do Reino Unido. Londres, hoje em dia, é a quinta ou sexta cidade francesa. Há mais franceses em Londres do que em Nice, o que é inacreditável. Podemos dizer que vamos cobrir Londres de maneira muito específica, pois há um enorme número de franceses que vive em Londres. De fato, há uma grande cobertura em Londres, há dois 
correspondentes em Londres, mas não vamos cobrir Londres em função dos franceses que vivem lá. Às vezes, há artigos escritos para contar sobre franceses que vivem em Londres, sobre o que faz um francês para encontrar uma moradia em Londres, por exemplo, porque isso concerne a muitas pessoas, isso pode acontecer. Da mesma maneira, podemos fazer um artigo sobre como um empreendedor francês poderia instalar uma filial no Brasil, uma filial do Carrefour, por exemplo, que é uma grande empresa francesa, para a qual o Brasil é muito importante. Mas nós não vamos considerar o leitor brasileiro do Le Monde como um público-alvo prioritário. Consideramos que o Brasil é um fator de atualidade importante a cobrir, assim como é importante cobrir a Argentina, a Venezuela, a Colômbia. Todos esses países são importantes, é preciso equilibrar tudo isso.

Revista Intercom - Sobre a escolha de temas. Podemos dizer que o meio ambiente é um tema importante para o mundo e, portanto, para Le Monde? Encontramos algumas matérias que relacionavam o Brasil e o meio ambiente, por exemplo, sobre a seca no país. Trata-se de um tema de importância mundial? Isso pode levar a pensar que são cobertos assuntos sobre um país cujo impacto vá além do país em questão?

Nouchi - Le Monde tem essa particularidade. Ao cobrir o mundo nas páginas internacionais, antes de chegar à política francesa, há sempre páginas que chamamos “Planeta” sobre o meio ambiente. E o problema climático no mundo é um problema muito, muito importante para nós. Há uma equipe inteira que trabalha sobre isso, sobre a questão do meio ambiente e a questão científica. Há um grande suplemento em ciência. Consideramos que essa questão é muito importante. Portanto, sua questão é evidentemente relevante. Há uma seca no Brasil. Vamos tratá-la de duas maneiras. Primeiro, isso se passa no Brasil, um país importante, de grande população etc. Mas é o exemplo da gravidade do que está se passando e pode ser que decidimos fazer esse artigo porque o pessoal da editoria de Ciências nos disse que é científico e há um estudo sobre o Brasil e, a partir disso, vamos construir algo sobre a seca no Brasil, tomada como um exemplo de consequência catastrófica do aquecimento global. E faremos isso de tempos em tempos, especialmente considerando que Trump decidiu sair do Acordo de Paris, contra toda a lógica. Então nós, de maneira voluntária, por uma decisão editorial, falaremos muito disso, pois pensamos que é um tema fundamental. Então, vamos nos servir do Brasil, mas também da seca no Sul do Sudão, por exemplo, lá acontece em proporção cataclísmica. Vamos trabalhar essa questão. Muitos jornalistas da editoria de Ciências, de Planeta, vão trabalhar essa questão porque a conhecem muito bem. Mas podemos demandar também uma abordagem da correspondente no Brasil, Claire Gatinois, se considerarmos importante fazer uma reportagem, fazer fotografia. Podemos dizer que temos a nossa própria leitura da atualidade, nossa própria maneira de hierarquizar a atualidade. Claro que não dizemos tudo da mesma maneira que um jornal de São Paulo ou outro jornal brasileiro. Fazemos da nossa maneira. É um jornal francês, portanto, com uma maneira francesa de ler a atualidade, mas de audiência internacional. 


\section{Referências bibliográficas:}

«Franck Nouchi, le médecin au Monde». Whatsupdoc Magazine. [12 jun. 2014]. Disponível em: <www. whatsupdoc-lemag.fr>. Acesso em: 05 abr. 2018.

MAINGUENEAU, D. Doze conceitos em Análise do Discurso. São Paulo: Editora Parábola, 2010.

Frases sem Texto. São Paulo: Parábola, 2014.

MEDINA, C. A. Entrevista: o diálogo possível. 2. ed. São Paulo: Editora Ática, 1990.

NOUCHI, F. Brésil: « Le Monde » a-t-il été partial? Le Monde, “Débats \& Analyses”, Paris, França, p.23, 25 abr. 2016.

MORAES, E. Aplicativos de notícias, destacabilidade e efeitos de sentidos: representações de identidades sobre o Brasil. 2017. 118 f. Relatório de Pesquisa no Exterior realizada na Université Paris Sorbonne (Paris IV), em Paris, França, sob a supervisão do prof. Dr. Dominique Maingueneau, no período de março a setembro de 2017. FAPESP Processo 2016/18915-3.

\section{Érika de Moraes}

Docente vinculada ao Departamento de Ciências Humanas da Faculdade de Arquitetura, Artes e Comunicação da Unesp de Bauru. Doutora em Linguística pelo Instituto de Estudos da Linguagem da Universidade Estadual de Campinas, IEL/Unicamp, com ênfase em Análise do Discurso de linha francesa. Com pós-doutoramento pela Université Paris-Sorbonne (Paris IV) sob supervisão do professor Dr. Dominique Maingueneau, realizado em 2017. Graduada em Comunicação Social, com habilitação em Jornalismo, pela Universidade Estadual Paulista, Unesp e em Letras pela Universidade do Sagrado Coração. Tem experiência nas áreas de Comunicação, Jornalismo, Letras e Linguística, com ênfase em ensino e pesquisa, além de histórico de atuação profissional em veículos de comunicação. Sua principal linha de pesquisa é a Análise do Discurso Francesa, possuindo artigos publicados em periódicos como Filologia e Linguística Portuguesa, Estudos Linguísticos, Calidoscópio, DELTA entre outros. É autora de capítulos em livros, como "Ethos Discursivo” (Editora Contexto) e organizadora do livro "Análise do discurso: conceitos essenciais e a contribuição de Dominique Maingueneau - análises práticas” (Canal 6 Editora). Atua na graduação em Comunicação e no curso de Especialização em Linguagem, Cultura e Mídia da FAAC, Unesp. E-mail: erika.moraes@faac.unesp.br. 